\title{
Cyberspace: A Communal Place or a Place of Separation?
}

\author{
Luciana Duranti \\ School of Library, Archival, and Information Studies \\ University of British Columbia \\ Vancouver, Canada \\ luciana.duranti@ubc.ca
}

\section{Summary}

Cyberspace, or the $5^{\text {th }}$ dimension, is regarded by most as a virtual space, though - as P. J. Rey states - "real-virtual dualism is nothing more than a fiction." The idea, he contends, comes from a refusal to accept the physical extension of digital information in computer terminals and other machines. Cyberspace is a physical space of separation between those who provide information and those who access it. Yet, many perceive it as a communal space where documentary facts, actions and memories are shared. As a result, policies that attempt to regulate the activities carried out in cyberspace, take two opposite directions: on the one hand they support open access, open data, transparent and open government, redundancy, and permanent preservation, and on the other hand they proclaim the right to oblivion, or to be forgotten, the right to privacy, the duty to confidentiality and secrecy, expungement of data or elimination of links, jurisdictional control of storage locations, as well as destruction of records after they have served their usefulness for the purposes they were generated. This keynote will discuss these directions in light of the findings of international research.

InterPARES Trust (ITrust) is an interdisciplinary collaborative research project which explores issues concerning digital records entrusted to the Internet, with the goal of generating the theoretical and methodological frameworks to develop local, national and international policies, procedures, regulations, standards and legislation, in order to ensure public trust grounded on evidence of good governance, a strong digital economy, and a persistent digital memory. ITrust is a research partnership that comprises over fifty universities and organizations, national and multinational, public and private, in North America, Latin America, Europe, Africa, Australasia, and Asia. Its researchers are experts in archival science, records management, diplomatics, law, information technology, communication and media, journalism, e-commerce, health informatics, cybersecurity, information governance and assurance, digital forensics, computer engineering, and information policy.

The studies carried out by the ITrust project have clearly shown that, whereas government and corporate bodies' policies can be ambiguous in terms of open- 
ness and restrictions, non-institutional/corporate users threat cyberspace as a true communal space, and this view of its function can be very powerful. This paper will discuss some of the 70 ITrust studies that reveal how users regard the Internet and identify some of the consequences.

Keywords: cyberspace, information providers, users, permanent preservation, right to be forgotten, InterPARES Trust 